\title{
UMA VASTA SURPRESA: OS PREFÁCIOS AO ROMANCE DE ZELDA SAYRE FITZGERALD
}

\author{
Marcela Lanius ${ }^{1 *}$ \\ Marcia A. P. Martins ${ }^{1 * *}$ \\ ${ }^{1}$ Puc-Rio, Rio de Janeiro, Rio de Janeiro, Brasil
}

Resumo

Este artigo discute, com o aporte teórico da vertente sociológica dos Estudos da Tradução, os prefácios e introduções em língua inglesa e portuguesa do único romance de Zelda Sayre Fitzgerald: Save me the Waltz, escrito e publicado em 1932. Analisaremos primeiro a identidade autoral da escritora tal como construída em seu sistema de origem - uma que é sobretudo negativa e que se consolida no prefácio de Harry T. Moore à edição de 1968 - e, em seguida, discutiremos o prefácio à tradução do romance, publicada apenas na década de 1980 no Brasil. Discutiremos o contexto histórico que circunda a produção do livro para averiguar em que medida a leitura do prefaciador brasileiro, Caio Fernando Abreu, difere da leitura de Moore e da crítica norte-americana da década de 1930 Palavras-chave: Zelda Fitzgerald; Save me the Waltz; Tradução Literária; Prefácios.

\section{“A VAST SURPRISE”: PREFACES TO ZELDA SAYRE FITZGERALD'S NOVEL}

Abstract

This article is informed by sociological approaches to translation in order to discuss the prefaces and introductions in both English and Portuguese of Save me the Waltz, Zelda Sayre Fitzgerald's only novel, written and published in 1932. We first analyze the author's identity such as it was built in her original literary system - an identity that is mostly negative, cemented in Harry T. Moore's preface to the 1968 English edition. Then, we discuss the preface to the Brazilian translation published in the 1980s,

\footnotetext{
* Graduada em Letras - Tradução (Inglês-Português) e Mestre em Estudos da Linguagem pela PUC-Rio. É Doutoranda em Estudos da Linguagem pela mesma instituição, com bolsa do CNPq. Tradutora, também atua como assistente editorial do periódico Tradução em Revista e é membro da F. Scott Fitzgerald Society desde 2017. Seu e-mail é: marcela.lanius@gmail.com. Registro ORCID: https://orcid.org/0000-0001-7390-0876

${ }^{* *}$ Doutora em Comunicação e Semiótica pela PUC-SP, tendo realizado estágio pós-doutoral na Queen Mary University of London em 2012. Tradutora e professora, atua nos cursos de formação de tradutores e no Programa de Pós-Graduação em Estudos da Linguagem da PUC-Rio. Organizou as coletâneas Tradução e multidisciplinaridade (Lucerna/PUC-Rio, 1999) e Visões e identidades de Shakespeare no Brasil (Lucerna, 2004), e é co-editora do periódico Tradução em Revista. Compilou a base de dados sobre traduções brasileiras do cânone dramático shakespeariano disponível em www.dbd.puc-rio.br/shakespeare, da qual é gestora. Entre as publicações recentes, incluem-se a co-organização da antologia bilíngue Palavra de tradutor / The Translator's Word (EdUFSC, 2018). Seu e-mail é: martins@domain.com.br. Registro ORCID: https://orcid.org/0000-0002-8663-1748
} 
considering the historical context surrounding the book's production. Our aim is to determine to what extent the Brazilian preface, written by Caio Fernando Abreu, differs from Moore's interpretation and the NorthAmerican criticism the novel received upon publication in the 1930s.

Keywords: Zelda Fitzgerald; Save me the Waltz; Literary Translation; Prefaces. 


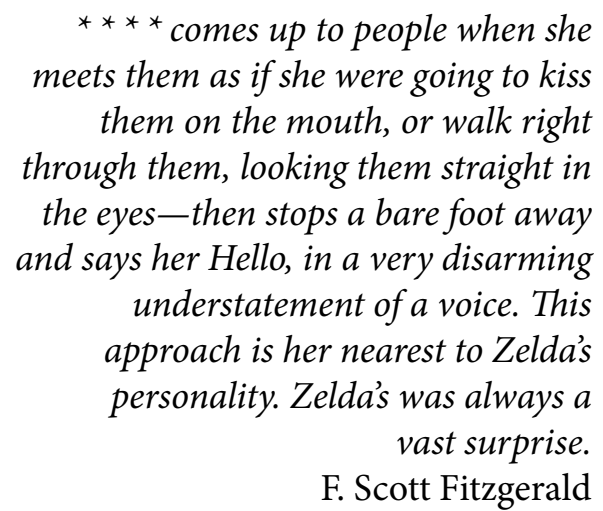

\section{Preâmbulo}

F. Scott e Zelda Fitzgerald parecem ser personagens confinados a momentos históricos específicos - a saber, a Era do Jazz, a Nova York no início dos anos 1920 e a comunidade de expatriados norte-americanos na França. Consagrados pelos jornais, pela crítica e pelos leitores da época como o grande escritor de uma nova geração e sua bela esposa - que em tempo se tornaria inspiração e modelo para todas as suas heroínas mais memoráveis (MILFORD, 1970, p. 77) -, os Fitzgerald representavam também a promessa de uma nova era dos Estados Unidos: a beleza e a majestade sulista que criara Zelda Sayre, afinal, agora firmava laços com o Norte católico de raízes irlandesas de Fitzgerald, e o glamouroso casal conquistaria riqueza e sucesso na recém-cosmopolita Nova York. ${ }^{1}$

Símbolos de uma narrativa esplendorosa e retratos pungentes do fracasso e da ruína, as identidades públicas do casal primeiro encantaram e, depois, afugentaram o público que tanto haviam cortejado naqueles primeiros anos da Era do Jazz (PRIGOZY, 2002, p. 26): de jovem casal de sucesso em 1920 a donos de um comportamento cada vez mais irregular e responsáveis pelo consumo excessivo de álcool em 1926 (BRYER \& BARKS, 2003, p. 59), os Fitzgerald são transmutados em escritor alcóolatra e esposa esquizofrênica em 1930 e, por fim, em estrelas de uma década esquecida nos anos finais de 1940.

Tendo em vista a relevância e a singularidade das narrativas biográficas do casal, curiosamente entrelaçadas às narrativas ficcionais por eles criadas, precisamos primeiro analisar brevemente os caminhos que levaram Zelda Sayre Fitzgerald até a condição de esposa e personagem menor, bem como a relevância de tal caracterização na construção e na recepção crítica de Save me the Waltz, para que em seguida possamos discutir os prefácios que selecionamos para o presente estudo.

\section{Retratos do passado}

Quando This Side of Paradise foi lançado, em 26 de março de 1920, F. Scott Fitzgerald era apenas um jovem aspirante a escritor que aguardava ansiosamente a chegada de sua noiva. A ainda adolescente Zelda Sayre, celebridade local na cidade de Montgomery, no Alabama, desembarcaria em Nova York uma semana mais 
tarde para selar o acordo feito (e uma vez já desfeito) dois anos antes com aquele soldado vindo do Norte. No entanto, a lua-de-mel que se seguiu ao casamento não foi um exílio romântico, mas sim o momento da consagração de Scott Fitzgerald como exímio especialista sobre as flappers. É cedo, portanto, que Fitzgerald associa os dois principais temas de sua escrita, a mulher e o dinheiro (BRYER \& BARKS, 2003, p. 6); e é cedo, também, que ele demarca sua jovem esposa de dezenove anos como eterna musa e personagem decorativa. A tarefa seria árdua, mas Zelda se considerava à altura do desafio - tanto que logo construiu para si mesma uma filosofia de vida que se assemelhava fortemente à de Gloria Gilbert, uma das personagens principais de The Beautiful and Damned (ou talvez fosse a filosofia desta que se assemelhasse à sua inspiração de carne e osso):

Aos vinte e um anos, Zelda havia formulado uma espécie de filosofia de vida; uma que era espantosamente similar à de Gloria. Tratava-se de uma perspicácia empresarial aplicada à feminilidade: era necessário inventar a si própria como um produto, para então expor-se com o tino de uma boa campanha publicitária. As mulheres deveriam dramatizar suas vidas enquanto ainda eram jovens, viver novas experiências e serem simplesmente felizes [...]. O que Zelda queria evitar, a qualquer custo, era o retrato daquelas mulheres infelizes, amarradas à vida doméstica exaustas e, mesmo assim, resignadas. (MILFORD, 1970, p. 92) ${ }^{2}$

O sucesso encontrado nos dois primeiros anos da década de 1920 mostrouse passageiro: em 1927, Fitzgerald já começava a se transformar em um escritor esquecido, forçado a publicar contos e a trabalhar para Hollywood; e Zelda, então com vinte e sete anos, encontrava sua identidade definida a partir das funções de esposa, mãe e antiga musa e inspiração. Decidida a traçar um caminho artisticamente independente do marido; um que pudesse lhe proporcionar não apenas uma ocupação diária, mas que também a ajudasse a definir, controlar e mesmo explicar aquela identidade que, por tanto tempo, havia sido utilizada como material para a ficção de Fitzgerald, ela recupera a primeira arte que havia aprendido ainda criança e que consolidara a sua posição de belle no estado do Alabama: o ballet.

O que à primeira vista poderia ser visto como uma ocupação saudável, no entanto, logo enfureceu Scott Fitzgerald. Se na Riviera Francesa e em Paris ele queixava-se de que não conseguia trabalhar com Zelda por perto, como nos contam os Murphy (MILFORD, 1970, p. 107) e Morril Cody (WAGNERMARTIN, 2004, p. 74-75), agora reclamava porque a esposa havia deixado de ser um mero "apêndice" - e se tornava, por isso mesmo, um "alvo de críticas" (WAGNER-MARTIN, 2004, p. 107). Conforme a Era do Jazz chegava ao seu fim, o casamento dos Fitzgerald também entrava em uma de suas maiores crises:

Os anos que Zelda havia dedicado ao ballet haviam, ironicamente, erradicado as faculdades que uma carreira como bailarina exigia: o vigor físico e a graça dos movimentos, além da sua juventude e beleza. 
A reputação de Scott como escritor começava a ser afetada pela demora em produzir um novo romance, e ele já havia adquirido o hábito de pegar empréstimos em dinheiro às custas de um material que ainda não havia escrito. (BRYER \& BARKS, 2003, p. 77) $)^{3}$

A poucos meses de completar trinta anos, Zelda Sayre Fitzgerald se viria obrigada a acrescentar outra alcunha à sua identidade de mulher: além de esposa, mãe e personagem, agora era também "louca". No dia 23 de abril de 1930, foi internada na clínica de Malmaison, localizada nos arredores de Paris, num estado de ansiedade extrema - e, mesmo tendo sido liberada no dia 2 de maio, seria internada novamente apenas duas semanas mais tarde, desta vez na clínica de Valmont. De lá, será transferida para Les Rives de Prangins, na Suíça, onde receberá oficialmente o diagnóstico de esquizofrenia (MILFORD, 1970, p. 158-159).

Scott Fitzgerald diria, mais tarde, que "a Suíça é uma terra na qual poucas coisas nascem, mas muitas chegam ao seu fim"4 (FITZGERALD, 2009, p. 123); de fato, a normalidade encerrada, para sempre perdida, daria lugar a alguns inícios e fins, como o súbito início das histórias e rememorações de antigos amigos e conhecidos sobre o sempre excêntrico comportamento de Zelda, que agora era rotulado como o comportamento de uma pessoa louca (WAGNER-MARTIN, p. 140); e o fim do ballet como ocupação, possível carreira ${ }^{5}$ ou simples atividade, uma vez que tanto Fitzgerald como os médicos acreditavam que a dança havia sido a culpada pelo colapso.

Liberada após quinze meses, Zelda então retornava ao papel de mãe e esposa - posto que o tratamento recebido era também uma "reeducação" para que fosse uma esposa melhor para Fitzgerald (MILFORD, 1970, p. 201) - e rumava para a sua cidade natal do Alabama; para uma existência na qual a ocupação que havia consumido os últimos anos de sua vida era agora apenas triste lembrança. É lá que, ainda fragilizada por conta da internação e afetada pela morte do pai, sofrerá um novo colapso. Desta vez, a clínica escolhida seria a Phipps Psychiatric Clinic do Johns Hopkins University Hospital, situada em Baltimore; o tratamento também seria outro.

Por mais que Zelda tenha tentado fugir das tentativas de terapia cognitiva propostas pelos médicos (BRYER \& BARKS, 2003, p. 145), a clínica de Phipps concedia espaço e material para que ela pudesse escrever não apenas cartas mas também o que bem entendesse. Em seis semanas, ela finalmente conseguiria contar por completo a história que melhor conhecia: a de sua própria vida (WAGNER-MARTIN, 2004, p. 123).

O manuscrito, que recebeu da escritora o nome de Save me the Waltz, já foi classificado de muitas maneiras: autobiografia, prosa experimental e ficção do trauma (LEGLEITNER, 2014, p. 124); exercício de autoanálise (BRYER \& BARKS 2003, p. 145) e mesmo autonarração (DIERMET, 1998). Qualquer que seja sua real classificação, o romance se constrói como tentativa concreta de uma mulher que olhava para o passado tentando compreender o presente - e sonhar com o futuro.

Dividida em quatro partes, cada uma subdividida em três seções, a narrativa de Zelda relata a vida de Alabama Beggs, caçula de uma família tão tradicional 
quanto os Sayre, que se apaixona por um jovem soldado durante a I Guerra Mundial - o aspirante a pintor David Knight. Ao longo do livro, acompanhamos os primeiros anos do casamento dos Knight, o nascimento da filha, Bonnie, a vida da família em Paris, o sucesso e a popularidade do casal dentro dos círculos artísticos de então e o desejo de Alabama em se tornar bailarina. Os ensaios desenfreados da personagem, bem como a sua determinação inabalável, são registrados com minúcia e sensibilidade:

À noite ela se sentava à janela cansada demais para mover-se, consumida pelo desejo de ter sucesso na dança. Parecia a Alabama que, ao atingir o seu objetivo, ela afastaria os demônios que a tinham dominado - que, ao se pôr à prova, conseguiria aquela paz que imaginava só existir com a autoconfiança --, que seria capaz, por intermédio da dança, de controlar suas emoções, de chamar $\mathrm{o}$ amor, a piedade ou a felicidade quando quisesse, tendo providenciado um canal por onde pudessem fluir. (FITZGERALD, 2014, p. 171)

Se na vida real Zelda Sayre Fitzgerald precisou abandonar o ballet por conta do seu colapso e consequente esquizofrenia, em Save me the Waltz Alabama Beggs precisa dizer adeus à recém-conquistada carreira como bailarina na cidade de Nápoles ${ }^{6}$ por conta de uma infecção no pé, que resulta em uma operação dos tendões. O romance chega ao fim com o casal de volta aos Estados Unidos - agora não mais em Nova York, mas sim na pequena cidade sulista que abre o romance. Alabama e David encerram o livro juntos, silenciosos, presos ao passado:

- É uma característica bem minha. Junto tudo num grande monte que rotulo de "o passado" e, depois de esvaziar dessa maneira esse profundo reservatório que foi um dia meu ser, estou pronta para continuar.

Ficaram sentados na obscuridade agradável do fim da tarde, olhando um para o outro através dos restos da festa. (FITZGERALD, 2014, p. 286-287)

\section{A recepção crítica de uma valsa dançada só}

A história da publicação de Save me the Waltz foi extensivamente documentada ao longo das cartas que os Fitzgerald trocaram durante o ano de 1932. É nessas cartas - bem como na correspondência de Scott Fitzgerald com o editor Maxwell Perkins - que fica aparente o real dano que o romance de Zelda provocou naquele que havia sido um dos grandes casamentos literários da década de 1920.

Furioso por descobrir que a esposa havia enviado um manuscrito diretamente para Perkins sem a sua autorização e irritado ao saber que o material contido no livro era uma narrativa espelhada no casamento dos dois até aquele momento, ${ }^{7}$ Scott Fitzgerald agora lutava para tentar preservar algo que, na sua opinião, pertencia unicamente a ele, o escritor profissional:

Zelda havia, pela primeira vez, invadido aquilo que Scott considerava ser o seu domínio, e a violenta reação que se seguiu era sintomática. O romance de Zelda era de uma intensa - e até mesmo ingênua - natureza 
autobiográfica, pois ela havia se inspirado na sua própria vida e, por consequência, no seu casamento com Scott: uma história que pertencia aos dois. Scott discordava fervorosamente. (MILFORD, 1970, p. 217) ${ }^{8}$

O que se segue é um intenso processo de revisão e edição, comandado por Scott (MILFORD, 1970, p. 224-225; BRYER \& BARKS, 2003, p. 164-165) com vistas não só a adequar o romance às expectativas do público leitor mas também a apagar as semelhanças mais fortes com o material que ele próprio estava utilizando no romance que viria a ser Tender is the Night.

Enfim publicado em outubro de 1932, Save me the Waltz não correspondeu às expectativas de Zelda, que via o romance como um primeiro passo para

tornar-se uma pessoa produtiva - para conquistar uma carreira e ganhar um salário que não só a ajudaria a construir uma identidade independente, mas também a se tornar uma mulher assalariada, e não mais um mero encargo financeiro para o marido. (BRYER \& BARKS, 2003, p. 146) ${ }^{9}$

Com apenas 1.392 cópias comercializadas, o livro foi um fracasso de vendas aniquilando, portanto, a independência financeira pela qual Zelda ansiava: após descontados o alto valor das revisões e parte da dívida de Scott com a editora, ela lucrou apenas cento e vinte dólares e setenta e três centavos (MILFORD, 1970, p. 264).

A recepção crítica também foi mista e decepcionante. Dos registros que sobrevivem, sabemos que William McFee, ao escrever sobre o livro para o New York Sun, conta que

[n] uma tentativa desesperada de ser enigmática e incomum ela acaba se assemelhando a uma criança insana. [...] $\mathrm{O}$ fato é que a autora tem apenas uma vaga noção do que significam muitas das palavras que utiliza, mas o efeito final desse acúmulo de metáforas fantásticas é realmente fascinante. (MILFORD, 1970, p. 263) $)^{10}$

A crítica publicada no The Bookman, por sua vez, aponta para o fato de que o maior problema do livro era a falta de revisão: "Os editores não só ignoraram a necessidade de pôr freio numa escrita tão exuberante, mas também não contrataram os serviços elementares de um revisor"11 (MILFORD, 1970, p. 263).

Projeto sensível de uma mulher que, naquele momento, não era mais flapper e muito menos esposa resignada, mas sim sujeito que tentava lidar com uma vida frustrada e uma doença debilitante, Save me the Waltz é talvez evidência contundente de que "para a mulher e para a artista moderna, as noções públicas de domesticidade continuavam inescapáveis" (LEGLEITNER, 2014, p. 125). ${ }^{12}$

\section{Um prefácio em 1968}

É curioso que, depois de uma juventude incendiária e dourada nos anos 1920, dos fracassos pessoais e literários dos anos 1930 e da prematuras mortes 
na década de 1940 (Scott faleceu em dezembro de 1940; Zelda, em março de 1948), os anos de 1950 tenham visto um novo interesse do público leitor pelos Fitzgerald. Como Brown (2017, p. 337-345) indica, as reedições de Gatsby e de alguns contos impressas para as tropas norte-americanas que lutavam durante a Segunda Guerra Mundial desfrutaram de um sucesso considerável - mas é somente na década de 1950 que um verdadeiro "Fitzgerald revival" começa a tomar forma, com a doação dos manuscritos de Fitzgerald à Universidade de Princeton e com o lançamento, em 1951, da primeira biografia sobre o autor: The Far Side of Paradise, de Arthur Mizener. Sucesso imediato de vendas, a biografia - que contava com a "benção" de Edmund Wilson (BROWN, 2017, p. 340) - foi devorada por leitores comuns e pelos círculos acadêmicos dos Estados Unidos, impulsionando não só reedições dos romances e contos de Fitzgerald como também estudos críticos sobre a sua obra.

Havia, no entanto, uma lacuna: a falta de estudos sobre a vida e a obra de Zelda, que continuava relegada a um papel menor e mesmo invisível dentro do "revival". Quando não era tratada com censura, como na biografia de Mizener (BROWN, 2017, p. 340), Zelda era relembrada em tons decididamente desfavoráveis por escritores já consagrados como Ernest Hemingway - que, em Paris é uma festa, publicado originalmente em 1964, a descrevera como uma esposa que tinha ciúmes do trabalho do marido e, por isso mesmo, tentava convencê-lo a não trabalhar (HEMINGWAY, 1978, p. 175-176). A idealização de uma Zelda invejosa, doente e louca perduraria no imaginário popular pelo menos até a década de 1970 - pois, como Ruth Prigozy (2002, p. 19) indica, "durante o início dos anos 1970, a popularidade dos relatos de Hemingway e Sheilah Ghaham moldaram as imagens dos Fitzgerald na cultura popular." ${ }^{13}$

Paralelamente à "redescoberta" dos Fitzgerald, no entanto, os Estados Unidos começavam a sentir os primeiros indícios do que hoje delimitamos como a segunda onda do movimento feminista - sobretudo com o lançamento do seminal The Feminine Mystique de Betty Friedan, em 1963. É dentro desse momento, portanto - que simultaneamente consagra uma imagem negativa de Zelda e que por outro começa a rever as identidades femininas na sociedade que Save me the Waltz receberá uma segunda edição.

$\mathrm{O}$ intervalo de trinta e seis anos entre as duas edições parece se justificar não só pelo apagamento e consequente retomada do interesse pelos Fitzgerald na cultura norte-americana, mas também pelo fato de que é apenas em 1953 que Save me the Waltz é lançado no Reino Unido, angariando boas críticas que, enfim, motivaram sua reedição em solo estadunidense (MOORE, 2014, p. iv).

A chance de revisitar essa obra tanto tempo depois de seu lançamento com vistas a conferir-lhe uma nova interpretação, no entanto, é perdida - em grande parte por conta do danoso prefácio que inaugura o livro, assinado pelo crítico e acadêmico Harry T. Moore. Ao apresentar o romance como "complementar" (MOORE, 2014, p. 295) ao romance de Scott Fitzgerald, Tender is the Night, o autor não só reaviva a briga doméstica dos Fitzgerald acerca do livro como também reitera uma das cisões mais profundas nascidas a partir desse conflito: 
a suposição de que Scott seria o autor profissional (e, portanto, aquele que teria o direito de escrever sobre o material autobiográfico do casal) e Zelda, a artista amadora. Segundo Moore, Zelda possuía apenas "um talento superficial para escrever, assim como possuía um talento pelo menos superficial para pintar e dançar" (MOORE, 2014, p. 295).

Inserido, portanto, na tradição que compara extensivamente Save me the Waltz ao último romance concluído de Scott Fitzgerald, Moore não só falha em examinar o livro como uma obra "distinta e independente daquela produzida pelo famoso parceiro"14 (LEGLEITNER, 2014, p. 124) como também lhe confere um novo rótulo: não mais relato autobiográfico ou exercício terapêutico, Save me the Waltz agora se transforma em "curiosidade literária" para leitores que desejam saber um pouco mais sobre a vida de F. Scott Fitzgerald:

Há muitos livros desse tipo, entre os quais um de especial interesse, porque diz respeito a contemporâneos dos Fitzgerald. O livro é The Journey Down, publicado em 1938 por Aline Bernstein, que foi a Esther Jack de alguns romances autobiográficos de Thomas Wolfe. The Journey Down, a obra de uma mulher sensível e talentosa, é apenas uma rasa repetição da vitalidade dos textos de Wolfe, mas o romance tem importância para aqueles que desejarem ler Wolfe a partir de um ângulo especial, o de uma mulher que o amava. [...] Mas, entre todos esses volumes, o de Zelda Fitzgerald se destaca por causa do intenso interesse que os leitores têm hoje em dia pela vida e obra de F. Scott Fitzgerald. (MOORE, 2014, p. 296 , grifos nossos)

Moore também consolida a imagem negativa - e, até então, hegemônica de Zelda no imaginário norte-americano:

Hemingway compreendeu que naquela família a mulher interferia constantemente no trabalho do marido porque tinha inveja dele. Seus desvairados esforços para se tornar pintora, bailarina e escritora eram parte dessa inveja. (2014, p. 297)

É provido desses argumentos que o crítico dedicará os últimos cinco parágrafos de seu prefácio não à uma análise de Save me the Waltz, mas sim ao enaltecimento de Tender is the Night. Louca, invejosa, silenciada - e, portanto, menor - é a Zelda Sayre Fitzgerald imortalizada no prefácio de sua própria obra; prefácio este que acompanhava, até 2001, as reedições em língua inglesa do livro.

Contudo, é importante notar que já em 1932 o romance de Zelda angariava admiradores. O crítico e escritor Malcolm Cowley, por exemplo, havia escrito para Scott Fitzgerald que Save me the Waltz muito o comovia:

há algo ali que nunca havia sido colocado em palavras. Mulheres que escrevem romances costumam ser do tipo que vive em retiros espirituais escondidos em cidadezinhas de interior e compra álcool barato nas ruas. Zelda tem uma outra história para contar. (MILFORD, 1970, p. 264) ${ }^{15}$ 
É justamente essa última crítica, então, que fomenta a seguinte pergunta: se mesmo dentro da identidade majoritariamente negativa de Zelda Sayre Fitzgerald existe espaço para uma leitura mais sensível da sua obra, é necessário investigar como Save me the Waltz - e sua autora - foram recebidos por outros olhares, outras culturas e outros idiomas. Seriam esses novos olhares mais próximos de Cowley ou de Moore? E seria a Zelda traduzida também tachada de artista menor?

\section{Reflexão teórica}

A investigação que se coloca ao final da seção acima concentra-se, neste presente estudo, em torno do prefácio à única tradução para o português de Save me the Waltz: Esta valsa é minha, publicada em 1986 e reeditada em 2014 pela Companhia das Letras - e assume, como aporte teórico para analisar não apenas o papel dos agentes envolvidos na tradução e na publicação do livro, mas também a identidade autoral de Zelda que é construída por esses agentes, uma perspectiva sociológica dos Estudos da Tradução; em especial, as discussões apresentadas por Casanova (2010), Heilbron \& Sapiro (2012), Milton \& Bandia (2008) e Sapiro (2008).

Contudo, é importante destacar que este estudo não pretende esgotar tal interseção entre o campo dos Estudos da Tradução e a obra de Zelda Fitzgerald traduzida para o português; pelo contrário. Propor um estudo sobre os prefácios de Save me the Waltz e Esta valsa é minha implica a realização de um recorte, posto que nosso objetivo é analisá-los enquanto elementos de proeminência dentro do livro físico - e como instrumentos que mediam o processo de leitura. Da mesma forma, é possível estipular que os prefácios, assim como as introduções e posfácios, contribuem para recriar (ou reforçar) imagens consagradas de um autor e de sua obra. É o caso do prefácio de Moore, que faz coro às alegações de Hemingway e relega o romance a algum lugar menor, complementar à Tender is the Night. Como Casanova afirma, afinal, o prefácio - tal como o ensaio crítico - também são espaços relevantes para os agentes criadores-consagradores (2010, p. 300); para os agentes intermediários que, segundo Sapiro (2008, p. 158), estão sempre presentes em qualquer processo de tradução como prática social.

É inegável, no entanto, o papel da tradução enquanto importante instrumento que assegura a presença de um autor e de uma obra em um outro sistema literário que não o de origem; enquanto mecanismo que garante a "existência internacional" identificada por Casanova, que permite a um escritor ou escritora

não apenas ser reconhecido como uma figura literária para além de suas fronteiras nacionais [mas que] também destaca a existência de uma posição internacional, autônoma, dentro do universo nacional (2010, p. 296). ${ }^{16}$

Nesse sentido, há que se ressaltar o importante papel de Rosaura Eichenberg enquanto tradutora de Save me the Waltz para o português, também ela uma importante criadora-consagradora, uma vez que assina a (até hoje) única tradução 
existente de uma obra de Zelda no Brasil. Além disso, é necessário considerar o alto capital simbólico que o seu nome confere a Esta valsa é minha, uma vez que Eichenberg é tradutora de longa carreira dentro do mundo da tradução literária - tendo trabalhado em versões para o português de obras hoje consideradas clássicas, como As aventuras de Huckleberry Finn (2011). Contudo, diferente do que acontece na tradução de Huck Finn, Eichenberg não deixa registros paratextuais em Esta valsa é minha - e, como até o momento de conclusão deste artigo, não conseguimos contato com a Companhia das Letras nem tampouco com a tradutora, a presente análise não pôde contemplá-la.

O aparente silêncio de Eichenberg nos elementos paratextuais de Esta valsa é minha, no entanto, não parece atestar para o que Casanova delimita como uma situação de "pouco poder de consagração"17 (2010, p. 301) de um agente - mas sim o ponto inicial de um futuro desdobramento deste estudo, como por exemplo uma análise sobre as escolhas tradutórias de Eichenberg ou mesmo um estudo comparativo ou de natureza historiográfica das traduções de Save me the Waltz para outros idiomas. O recorte deste estudo, portanto, é apenas um de muitos possíveis.

\section{Um prefácio em 1986}

Antes de chegarmos ao prefaciador de Esta valsa é minha, no entanto, é necessário primeiro avaliar a relação entre as línguas envolvidas neste estudo - a saber, o inglês e o português - e delimitar alguns fatores importantes que circundam a publicação do livro.

Se adotarmos a nomenclatura utilizada por Casanova (2010) e por Heilbron \& Sapiro (2012) de idiomas dominantes e idiomas dominados, podemos então especificar que a tradução de Save me the Waltz para o português é uma tradução "para um idioma dominado de um texto escrito em um idioma dominante"18 (CASANOVA, 2010, p. 290). Neste cenário, portanto, o inglês assumiria a posição de idioma dominante e o português, por sua vez, assumiria a posição de idioma dominado, enquadrando-se especificamente no quarto e último grupo descrito por Casanova: o de idiomas que têm grandes tradições literárias e um elevado número de falantes, mas que são pouco conhecidos no campo literário mundial (2010, p. 289).

Nesse sentido, então, a relação que se estabelece por ocasião da tradução de Save me the Waltz é uma que não só "corre do centro para a periferia"19 (HEILBRON \& SAPIRO, 2012, p. 96), mas que também afirma a posição "hipercentralizada"20 (idem) do inglês. Se acrescentarmos a tal panorama o fato de que o Brasil possui uma forte tradição de literatura traduzida que vem desde o boom tradutório das décadas de 1940 e 1950 identificado por Paes (1990), podemos avaliar em mais detalhes as condições que trazem primeiro Scott Fitzgerald e, mais tarde, Zelda Fitzgerald para a língua portuguesa e para a cultura brasileira.

O primeiro ponto de interseção está no "Fitzgerald revival" identificado por Brown (2017) nos Estados Unidos dos anos 1950. Se em janeiro de 1953 a coluna "Teatrinho das letras" do Correio da Manhã ${ }^{21}$ declarava a "redescoberta de F. Scott Fitzgerald", dizendo que "resta agora que se descubra um editor brasileiro" 
para suas obras, em 1959 o mesmo jornal noticiava as novas traduções francesas das obras de Fitzgerald e, em março de 1962, o Última Hora do Rio de Janeiro anunciava a tradução de Tender is the Night.

Save me the Waltz, por sua vez, chega ao Brasil na década de 1980 como item daquele que viria a ser o primeiro lote de $\operatorname{livros}^{22}$ da Companhia das Letras. Como conta a reportagem de Toni Marques para o Jornal do Brasil em outubro de 1986, Luís Schwarz, editor responsável pela empresa, retornava da Feira de Frankfurt com diversos novos livros para publicação - e com dois outros que ele obteve "bem antes da feira". Um deles era Save me the Waltz, "único romance de Zelda Fitzgerald, mulher do escritor norte-americano F. Scott Fitzgerald."

Como editor, então, Schwarz parece ter desempenhado papel bastante relevante na sua condição de agente - compactuando com a proposição de Sapiro de que os editores "têm um papel importante na circulação internacional de livros"23 (2008, p. 154). Dado o tamanho ainda diminuto da Companhia das Letras à época e o seu cuidado com a questão da tradução - em 1989, a editora agradeceria aos seus sessenta tradutores pelos três anos de sucesso em uma página do Jornal do Brasil ${ }^{24}$-, é possível inferir que Schwarz tenha sido o responsável não só por atribuir a tarefa de tradução a Eichenberg, mas também pela encomenda do prefácio a um de seus autores: seu amigo ${ }^{25}$ Caio Fernando Abreu, ele próprio grande admirador da vida e da obra de Zelda Fitzgerald.

De fato, é possível verificar que Zelda recebe algumas menções significativas ao longo de toda a correspondência do escritor gaúcho. Em carta ${ }^{26}$ à amiga Maria Lídia Magliani datada de 1994, por exemplo, ele relata a primeira internação após o diagnóstico de soropositivo: "acordei nu amarrado pelos pulsos numa maca de metal... Frances Farmer, Zelda Fitzgerald, Torquato Neto: por aí."

Em outra carta, escrita em maio de 1982 para Sonia Coutinho, ele brinca que vive sozinho com Zelda Fitzgerald, sua gata que "adora gim"; e, anos mais tarde, em 10 de outubro de 1985, relataria a Sérgio Keuchgerian a visão que tinha de sua estante de livros:

E posso ver na estante assim, de repente, todo o Proust, e muito Rimbaud, e Verlaine, Faulkner, Italo Svevo, William Blake (...).

Zelda, há também o único romance escrito por Zelda Fitzgerald, a mulher de Scott Fitzgerald, que morreu louca, um incêndio, um hospício. Chamase Save me the Waltz. Reserve-me a valsa, não é lindo? (...)

Please, save me the waltz. (MORICONI, 2016)

É possível, ainda, localizar temporalmente a agentividade de Caio Fernando Abreu entre os anos de 1983 e 1986 - período no qual o escritor atua tanto como o agente evidenciado por Milton \& Bandia quanto como o criador-consagrador de Casanova.

Em 29 de outubro de 1983, Abreu recebia a notícia do suicídio da poeta Ana Cristina Cesar, sua amiga próxima. Passados três anos, ele ainda se lembrava de Cesar em uma crônica publicada n'O Estado de São Paulo. No dia 17/09/1986, comenta: 
Semana passada, fez exatamente três anos que vi Ana C. pela última vez. Chovia no alto do morro de Santa Teresa, no Rio. Era noite de meu aniversário. Ela tocou um por um todos os objetos de meu quarto, sem dizer nada. Depois se foi, para sempre. (ABREU, 2012, p. 45)

Logo em seguida, ele menciona que estava lendo a coletânea de inéditos de Cesar, publicada postumamente em 1985, na qual um poema, em especial, merece destaque: "Ricas e famosas", que se encerra com os seguintes versos: "Chamem os bombeiros, gritou Zelda./Alegria! Algoz inesperado" (CESAR, 1985, p. 189).

O poema, portanto, não só registra a fascinação de Ana Cristina Cesar por Zelda mas também recupera uma imagem relatada por Arthur Mizener em The Far Side of Paradise, especialmente relevante para Cesar e Abreu: "Certa noite, entediada, Zelda acionou os bombeiros e, quando eles entraram pelo apartamento perguntando onde estava o fogo, ela bateu no peito de forma dramática e disse, 'Aqui."' (MIZENER, 1951, p. 121). ${ }^{27}$

No dia $1^{\circ}$ de outubro de 1986, apenas uma semana após publicar a crônica acima mencionada, Abreu publicaria uma outra: "Um sonho regado a gim", na qual anuncia o lançamento de Esta valsa é minha para o final daquele mês. É nessa crônica, portanto, que o escritor apresentará a Zelda escritora para o público brasileiro - ainda que acabe reproduzindo algumas das declarações que hoje já sabemos serem falsas. Um exemplo é a suposta "ambição" de Zelda, que "sonha[va] com uma vida cheia de aventuras, longe dali, daquela detestável cidadezinha perdida no Sul dos Estados Unidos" (ABREU, 2012, p. 47).

As cartas da própria Zelda, no entanto, mostram uma adolescente bem menos gananciosa, apegada à sua cidade natal: “- Eu queria que você pudesse ver Montgomery como ela é - sem aquele acampamento militar que bagunçava tanto as coisas - acho que assim você entenderia porque eu a amo tanto - "28 (BRYER \& BARKS, 2003, p. 25). Em outra carta, ela diria ainda sobre a Nova York que a receberia: "Eu queria que Nova York fosse uma cidadezinha bem pequenininha - só para que eu pudesse imaginá-la. Não faço a menor ideia de como ela é" (idem, p. 39).

Movimento semelhante se dá quando Abreu, possivelmente cativado pela narrativa de decadência e esquecimento dos Fitzgerald, ecoa a narrativa de muitos biógrafos e historiadores: "Zelda tinha-se tornado uma mulher cara. Scott precisou começar a vender sua literatura para sobreviver. Ela ficou estranha, obcecada pela dança. Fazia aulas o dia todo, até que enlouqueceu e foi internada. Ele afundou no álcool, vendeu-se a Hollywood" (ABREU, 2012, p. 48).

No entanto, é também nessa crônica que o gaúcho delimitará Zelda não mais como "apêndice" (WAGNER-MARTIN, 2004, p. 74) e sombra menor de uma grande personalidade, mas sim como rainha por sua própria majestade sulista: "Eram dois eleitos dos deuses se defrontando, cada um com sua nobreza, com sua coroa invisível, mas nítida" (ABREU, 2012, p. 47). O último parágrafo descreve Save me the Waltz como um romance que, de fato, tem algo a dizer: 
Pois, como eu ia dizendo, era uma vez uma moça que acabou escrevendo um romance meio desconjuntado, nervoso e perturbador, em que conseguiu deixar duramente claro que os deuses costumam cobrar um alto preço de seus favoritos. Na primeira frase do livro, alguém diz: "Essas garotas acham que podem fazer qualquer coisa e ficar impunes". Não podem. A moça Zelda-Alabama, por exemplo, não ficou. Ninguém fica. Nem nós. (ABREU, 2012, p. 48)

Mas é no seu prefácio a Esta valsa é minha, no entanto, que Abreu aprofundará a leitura sobre Zelda que havia esboçado na crônica acima. Em um novo texto, Abreu introduz uma Zelda que, não mais invejosa (como Moore havia afirmado), escreve "para se justificar, para se compreender, para se salvar. Para orientar a si própria dentro daquele poço onde tinha caído e que, até hoje, por falta de outra palavra mais adequada, chamamos de 'loucura"' (ABREU, 2014, p. 291-292).

Não mais obra de pouco valor de uma artista amadora, Save me the Waltz é, para Abreu, a "luta para deixar de ser a sombra, embora fascinante, do escritor mais mimado e talentoso de seu tempo" (ABREU, 2014, p. 292); uma

tentativa, apesar das mutilações, de continuar a vida. Com seus cortes bruscos, seus diálogos derramados e técnica às vezes desconjuntada, mas encharcado de emoção e entrega, o livro flui. (...) Depois dele, é possível compreender melhor aquela velha história de Zelda chamando os bombeiros, trancada num quarto de hotel em Paris. (p. 293)

Abreu indica também que é com Save me the Waltz que os versos de Ana Cristina Cesar ganham nova vida:

E é então, também, que se pode compreender aqueles versos de Ana Cristina Cesar: "Chamem os bombeiros, gritou Zelda./ Alegria! Algoz inesperado". Não, essas garotas não podiam mesmo ficar impunes dizem todos. E veja só: Sylvia Plath, Ana Cristina Cesar, Zelda Fitzgerald e Alabama Knight - para ficarmos só nessas quatro - não ficaram. Mas deixaram versos, histórias. E lendas. Que talvez não existissem, se elas bravas garotas - não tivessem ousado ir muito além do mediocremente permitido. (p. 293)

Por último, destacamos ainda o marco final da agentividade do escritor gaúcho: o ano de 1988, que marca o lançamento de seu livro de contos Os dragões não conhecem o paraíso. A primeira edição do livro é dedicada a vários amigos de Abreu - entre eles, Ana Cristina Cesar. Curiosamente, é também ela que encerra o livro, e com um verso aqui mencionado: "Chamem os bombeiros, gritou Zelda./ Alegria! Algoz inesperado".

Ao assumir a posição de prefaciador, então, Abreu se coloca não mais como apenas admirador da autora, mas também como um agente; como um criadorconsagrador, detentor de um papel ativo nos processos de mediação da leitura e reavaliação da identidade autoral de Zelda. Nesse sentido, Abreu confirma a fala de Casanova: "é por serem autores consagrados que esses agentes consagradores 
'recriam' obras e acabam se tornando comentadores privilegiados das obras que traduzem e/ou consagram." (2010, p. 301). ${ }^{29}$

É importante destacar, no entanto, que não é só o prefácio de Abreu que se mostra mais receptivo à obra de Zelda, posto que a crítica brasileira da década de 1980 também a recebeu com entusiasmo. Silvia Cintra Franco (1987), por exemplo, ressalta em sua crítica na Mulherio o aprisionamento de Zelda/Alabama dentro da sociedade patriarcal do início do século:

Zelda e Alabama Knight não ficaram impunes. Pagaram com a sanidade mental, num hospital de doenças nervosas, a primeira; e com a enfermidade, a segunda. Pagaram por sua ousadia e obsessão: o sucesso. Meta proibida à mulher, a quem a sociedade destina o papel de princesa de seu homem, e este, por sua vez, lhe impõe manter-se "fechada para sempre numa torre de marfim para meu deleite particular". Duvidoso galanteio que lhe dirige o enamorado David Knight/Scott Fitzgerald. (p. 8)

Por sua vez, a crítica de Roberto Muggiati na revista Manchete, também de 1987, não só discute a consagração negativa de Zelda como "artista menor, bloqueada pela esquizofrenia" (1987, p. 78), mas também destaca um importante marco histórico - este, especialmente relevante para a análise do presente estudo: o já mencionado movimento feminista nos anos 1960 e 1970. Nesse sentido, é importante demarcar que o prefácio de Caio Fernando Abreu não deve ser visto como ocorrência isolada - mas sim como parte de um movimento muito maior de recuperação de vidas e obras de mulheres que haviam sido esquecidas dentro daquilo que Castro (2017, p. 230) identifica como o "cânone patriarcal" da literatura.

No que diz respeito à recuperação da obra de Zelda, é possível destacar algumas obras fundamentais, como a biografia Zelda, escrita em 1970 por Nancy Milford - primeira obra de fôlego a investigar a condição de Zelda enquanto esposa, criação do marido, e mulher doente e a propor uma análise crítica de sua obra literária; o estudo de Jacqueline Tavernier-Courbin de 1979, intitulado "Art as a Woman's Response and Search: Zelda Fitzgerald's Save me the Waltz"; o artigo de Elizabeth A. Waites de 1986, "The Princess in the Tower: Zelda Fitzgerald's Creative Impasse" e, por fim, a compilação dos Collected Writings lançada em 1991 com uma importante introdução de Mary Gordon - na qual a autora questiona a dificuldade em admitirmos Zelda como autora: "Por que será que nos sentimos tentados a tomar as dores de Scott Fitzgerald e negar à Zelda Fitzgerald a prestigiosa condição de escritora?"30 (FITZGERALD, 1991, p. xvii)

Dessa forma, podemos estabelecer que Abreu, Eichenberg e Schwarz se alinham à mudança de paradigma vivenciada nos Estados Unidos, num movimento que se afasta da leitura de Moore e da crítica dos anos 1930.

\section{Novas valsas}

O pequeno conjunto de obras acima delineado vem crescendo significativamente nos últimos anos: o lançamento de obras como Dear Scott, 
Dearest Zelda (2003), que conta com introduções e comentários atentos à condição de Zelda enquanto mulher presa às amarras sociais de seu tempo; a biografia Zelda Sayre Fitzgerald: An American Woman's Life (2004), de Linda WagnerMartin, e o número cada vez maior de artigos críticos sobre a obra de Zelda, como "The Cult of Artistry in Zelda Fitzgerald's Save me the Waltz" (2014), de Rickie-Ann Legleitner e "The Muse and the Maker: Gender, Collaboration, and Appropriation in the Life and Work of F. Scott and Zelda Fitzgerald", de Ashley Lawson (2015) - além da presença de Zelda em obras ficcionais como Z: A Novel of Zelda Fitzgerald (2013), de Therese Anne Fowler, Bobbed Hair and Bathtub Gin: Writers Running Wild in the Twenties (2005), de Marion Meade e Superzelda: The Graphic Life of Zelda Fitzgerald (2013), de Tiziana Lo Porto e Daniele Marotta -, atestam para um novo "Fitzgerald revival"; um que tem, como estrela, não mais o marido e sim a esposa.

No ano em que a obra de Zelda entra em domínio público, é possível especular que começa a se concretizar o movimento destacado por Sapiro (2008, p. 155) de que o "reconhecimento simbólico dos pares pode, a longo prazo, resultar na consagração de um texto e de seu autor"31 - afinal, no início de 2019 Save me the Waltz foi relançado em língua inglesa pela recém-estabelecida Handheld Press, com uma nova introdução.

Assinado por Erin E. Templeton, este novo elemento paratextual substitui o prefácio danoso de Moore, indicando algumas leituras sobre a vida e a obra de Zelda, além de retomar criticamente a posição da escritora dentro do casamento dos Fitzgerald: "ela viveu em um mundo no qual as mulheres casadas deveriam se contentar com as funções de esposa e mãe" (TEMPLETON, 2019, p. x). ${ }^{32}$

Templeton entende Save me the Waltz como uma narrativa na qual "a personagem principal se equilibra entre o velho e o novo de maneiras diversas" (2019, p. xvii), ${ }^{33}$ ecoando a queixa da própria Alabama Beggs: "é muito difícil ser duas pessoas distintas ao mesmo tempo" (FITZGERALD, 2014, p. 79). De fato, Zelda Fitzgerald ainda ocupa uma posição dual: entre o velho e o novo, entre artista e mulher doente, entre criadora e criação. Dona de uma história de vida digna de filmes e detentora de talentos singulares, Zelda nos faz recorrer não só à sua biografia, como Mary Gordon ${ }^{34}$ nos lembra, mas também à sua obra; e, claro, aos seus interlocutores, agentes e tradutores.

\section{Notas}

1. Vale relembrar o vívido retrato de Gilbert Seldes sobre o casal: "Suddenly, as though in a dream, this apparition, this double apparition, approached me. The two most beautiful people in the world were floating toward me, smiling. It was as if they were angelic visitors" (Milford, 1970, p. 97).

2. "At twenty-one Zelda had formulated a sort of philosophy of life; it was remarkably like Gloria's. It was an application of business acumen to femininity: you created yourself as a product and you showed yourself with all the flair of a good advertising campaign. Women were to dramatize themselves in their youth, to experiment and be gay; in their old age (in their forties) they would be magically content. What Zelda intended to avoid at all costs was her vision of the legion of unhappy women, saddled with domesticity, weary and yet resigned to it." 
3. "Zelda's years of ballet had depleted the very resources such a career demanded her physical stamina and grace, along with her youth and beauty. Scott's reputation as a writer was also suffering while the public waited for him to produce another novel, and he had already developed the habit of borrowing against future work."

4. "Switzerland is a country where very few things begin, but many things end".

5. Em setembro de 1929, Zelda havia recebido um convite da San Carlo Opera Ballet Company para dançar o solo de Aida durante uma temporada inteira na cidade de Nápoles; no entanto, naquilo que Wagner-Martin indica como "the most critical gap" (2004, p. 125) da biografia dos Fitzgerald, não temos a resposta de Zelda e muito menos qualquer registro deixado por Scott sobre o assunto. Sabemos apenas que ela recusou o convite - e que, meses mais tarde, estava internada.

6. O romance, portanto, funciona como a resposta nunca encontrada pelos biógrafos: por mais que tenha recusado o convite na vida real, na ficção ela aceita e se muda para Nápoles - sozinha.

7. O teor autobiográfico é tão latente que, no rascunho enviado para Perkins, David Knight recebera o nome de Amory Blane - o personagem principal de This Side of Paradise e aquele que mais se assemelhava a Scott (BRYER \& BARKS, 2003, p. 165).

8. "Zelda had for the first time directly invaded what Scott considered his own domain, and the violence of his reaction was telling. Her novel was intensely, even naïvely autobiographical, and as she drew on her own life, so she drew on her life with Scott, for it was her material as well as his. Scott strenuously disagreed."

9. "become a productive person - to establish herself in a career and to earn money that would allow her to have an independent identity that would make her selfsupporting, rather than a constant financial burden."

10. "In the desperate attempt to be contrary and enigmatic she resembles an insane child.... The author occasionally has only the vaguest notion of the meanings of many words she uses, but the effect of the accumulated fantastic metaphors is fascination for all that."

11. "It is not only that her publishers have not seen fit to curb an almost ludicrous lushness of writing but they have not given the book the elementary services of a literary proofreader."

12. "the communal notions of domesticity remained inescapable for the independent modernist woman and artist alike"

13. "During the early 1970s, the influence of Hemingway's and of Sheilah Graham's revelations shaped the popular culture images of the Fitzgeralds."

14. "distinct and independent from that of her famous partner".

15. "moves me a lot: she has something there that nobody got into words before. The women who write novels are usually the sort who live spiritually in Beloit, Wisconsin, even when they are getting drunk at the Select. Zelda has a different story to tell."

16. "not only to be recognized as a literary figure outside his or her national borders, but even more importantly it brings into existence an international position, an autonomous position inside the national universe."

17. "little consecrating power".

18. "into a dominated language of a text written in a dominating language".

19. "[flows] from center to periphery".

20. "hyper-central". 
21. Este jornal, assim como os demais aqui citados, foram acessados por meio da Hemeroteca Digital.

22. A informação é dada por Roberto Muggiati na crítica "Esta valsa é de Zelda" para a revista Manchete em 1987.

23. "publishers play a major role in the international circulation of books".

24. O recorte em questão pode ser acessado em http://memoria.bn.br/docreader/ DocReader.aspx?bib=030015_10\&pagfis $=204953$

25. Schwarz era editor de Abreu desde 1982, quando lançaram juntos Morangos Mofados. Os dois desenvolveram uma longa amizade, como relatado em Dip (2009).

26. As cartas citadas nesta seção estão publicadas no livro organizado por Moriconi (2016), atualmente disponível apenas em e-book e sem numeração específica de páginas.

27. "One night, out of some kind of boredom, Zelda put in a fire alarm and when the department arrived an asked where the fire was, she struck her breast dramatically and said, 'Here."

28. "- I wish you could get a glimpse of Montgomery like it really is - without the camp disturbing things so - and you'd know why I love it so -". "I wish New York were a tiny little town - so I could imagine how it'd be. I haven't the remotest idea of what it's like".

29. it is because they are themselves consecrated authors that these great consecrators 're-create' works, and often become privileged commentators on the works that they translate and/or consecrate".

30. "Why is it that we are tempted to ally ourselves with Scott Fitzgerald and deny Zelda Fitzgerald the valorized place of writer?"

31. "symbolic recognition by peers is likely in the long run to result in a greater consecration of the text and its author".

32. "she lived in a world where married women were expected to be content in their roles of wife and mother".

33. "the main character is poised between the old and the new in many different ways"

34. FITZGERALD, 1991, p. xv.

\section{Referências}

ABREU, C. F. A vida gritando nos cantos: crônicas inéditas em livro (1986 - 1996). Rio de Janeiro: Nova Fronteira, 2012.

ABREU, C. F. Prefácio. In: FITZGERALD, Zelda. Esta valsa é minha. Tradução de Rosaura Eichenberg e prefácio de Caio Fernando Abreu. São Paulo: Companhia das Letras, 1986.

ABREU, C. F. Os dragões não conhecem o paraíso. São Paulo: Companhia das Letras, 1988. 1ª edição.

CESAR, A. C. Inéditos e dispersos. São Paulo: Editora Brasiliense, 1985.

BROWN, D. S. Paradise Lost: A Life of F. Scott Fitzgerald. Cambridge/London: The Belknap Press of Harvard University Press, 2017.

BRYER, J. R. \& BARKS, C. W. (Orgs.). Dear Scott, Dearest Zelda: The Love Letters of F. Scott and Zelda Fitzgerald. London: Bloomsbury, 2003.

CASANOVA, P. Consecration and Accumulation of Literary Capital: Translation as Unequal Exchange. Translated by Siobhan Brownlie. In: BAKER, M. (Ed.). 
Critical Readings in Translation Studies. London and New York: Routledge, 2010, p. 285-303.

CASTRO, O. (Re)examinando horizontes nos estudos feministas de tradução: em direção a uma terceira onda? Tradução de Beatriz Regina Guimarães Barboza. TradTerm, Vol. 29, p. 216-250, julho de 2017.

DIERMET, B. The Death of the Author: F. Scott Fitzgerald and "The Last Tycoon". In: The Journal of Narrative Technique. Vol. 28, no 2 (Spring 1998) p. $134-160$. Disponível em: <https://www.jstor.org/stable/30225489>.

DIP, P. Para sempre teu, Caio F. - cartas, memórias, conversas de Caio Fernando Abreu. Rio de Janeiro: Editora Record, 2009.

FITZGERALD, F. S. The Crack-Up. Edited by Edmund Wilson. New York: New Directions, 2009.

FITZGERALD, F. S. The Great Gatsby. Great Britain: Penguin Popular Classics, 1994.

FITZGERALD, Z. Esta valsa é minha. Tradução de Rosaura Eichenberg. São Paulo: Companhia das Letras, 1986.

FITZGERALD, Z. Esta valsa é minha. Tradução de Rosaura Eichenberg. São Paulo: Companhia das Letras, 2014. $2^{\text {a }}$ edição.

FITZGERALD, Z. The Collected Writings of Zelda Fitzgerald. Edited by Matthew J. Bruccoli. Alabama: The University of Alabama Press, 1991.

FITZGERALD, Z. Save me the Waltz. Carbondale, Illinois: Southern Illinois University Press, 1967.

FITZGERALD, Z. Save me the Waltz. London: Vintage Books, 2001.

FITZGERALD, Z. Save me the Waltz. Preface by Erin E Templeton. Great Britain: Handheld Press, 2019.

FOWLER, Therese Anne. Z: A Novel of Zelda Fitzgerald. New York: St. Martin's Griffin, 2013.

FRANCO, S. C. Cidadã ousada de segunda classe. Mulherio. São Paulo, ano VII, nº 30. 1987, p. 8. Disponível em <http://memoria.bn.br/docreader/459488/686>. Acesso em 09 abr 2019.

HEILBRON, J. Towards a Sociology of Translation: Book Translation as a Cultural World System. In: BAKER, M. (Ed.) Critical Readings in Translation Studies. London/New York: Routledge, 2012. p. 305-316.

HEILBRON, J.; SAPIRO, G. Translation and the Field of Publishing. Translation Studies. 1:2, p. 154-166, 2008.

HEMINGWAY, E. Paris é uma festa. Tradução de Ênio Silveira. Rio de Janeiro: Editora Civilização Brasileira, 1978. 4a edição.

LAWSON, A. The Muse and the Maker: Gender, Collaboration, and Appropriation in the Life and Work of F. Scott and Zelda Fitzgerald. The F. Scott Fitzgerald Review. vol. 13, no 1, p. 76-109, 2015.

LEGLEITNER, R.-A. The Cult of Artistry in Zelda Fitzgerald's Save me the Waltz. The F. Scott Fitzgerald Review. vol. 12, no 1, p. 124-142, 2014.

LETRAS ESTRANGEIRAS. Correio da Manhã, 20 de junho de 1959. Disponível em: <http://memoria.bn.br/docreader/DocReader.aspx?bib=089842_06\&pagf is $=107261>$. Acesso em 09 abr 2019.

LO PORTO, T.; MAROTTA, D. Superzelda: The Graphic Life of Zelda Fitzgerald. New York: One Peace Books, 2013. 
MARQUES, T. Os estrangeiros já estão chegando. Jornal do Brasil, 18 de outubro de 1986. p. 8-9. Disponível em: <http://memoria.bn.br/docreader/DocReader.aspx? bib=030015_10\&pagfis=126204>. Acesso em 09 abr 2019.

MEADE, M. Bobbed Hair and Bathtub Gin: Writers Running Wild in the Twenties. New York: Harcourt Books, 2005.

MILFORD, N. Zelda: A Biography. New York: Harper Perennial, 1970.

MILTON, J.; BANDIA, P. Introduction. In:___ . Agents of Translation. Amsterdam/ Philadelphia: John Benjamins, 2008, p. 1-18.

MIZENER, A. The Far Side of Paradise: A Biography of F. Scott Fitzgerald. London: Eyre \& Spottiswoode, 1951.

MOORE, H. T. Prefácio. In: FITZGERALD, Z. Esta valsa é minha. Tradução de Rosaura Eichenberg. São Paulo: Companhia das Letras, 2014. $2^{\mathrm{a}}$ edição.

MORICONI, Í. (Org). Cartas de Caio Fernando Abreu. Editora E-Galáxia, 2016. $2^{\mathrm{a}}$ edição. E-book. ISBN: 9788584741441 . Disponível em: <http://www.e-galaxia. com.br/produto/cartas/>. Acesso em 10 out. 2018.

MOVIMENTOS \& BASTIDORES. Última Hora, 15 de março de 1962. Disponível em: $<$ http://memoria.bn.br/docreader/DocReader.aspx?bib=386030\&pagfis=77235>. Acesso em 09 abr. 2019.

MUGGIATI, R. Esta valsa é de Zelda. Revista Manchete. Rio de Janeiro, nº 1813, ano 35. 1987, p. 78-79.

PAES, J. P. Tradução: a ponte necessária. São Paulo: Editora Ática, 1990.

PRIGOZY, R. Introduction: Scott, Zelda, and the culture of celebrity. In:

(Ed.) The Cambridge Companion to F. Scott Fitzgerald. New York: Cambridge University Press, 2002, p. 1-27.

TAVERNIER-COURBIN, J. Art as a Woman's Response and Search: Zelda Fitzgerald's Save me the Waltz. Southern Literary Journal, 11:2, p. 22-42, 1979.

TEATRINHO DAS LETRAS. Correio da Manhã, 3 de janeiro de 1953. Disponível em: <http://memoria.bn.br/docreader/DocReader.aspx?bib=089842_06\&pagf is $=23149>$. Acesso em 09 abr 2019.

TEMPLETON, E. E. Introduction. In: FITZGERALD, Z. Save me the Waltz. Great Britain: Handheld Press, 2019.

TWAIN, M. As Aventuras de Huckleberry Finn. Tradução de. Rosaura Eichenberg. Porto Alegre: L\&PM, 2011.

TURNBULL, A. Scott Fitzgerald. New York: Charles Scribner's Sons, 1962.

WAGNER-MARTIN, L. Zelda Sayre Fitzgerald: An American Woman's Life. Great Britain: Palgrave Macmillan, 2004.

WAITES, E. A. The Princess in the Tower: Zelda Fitzgerald's Creative Impasse. Journal of the American Psychoanalytic Association, 34:3, p. 637-662, 1986.

WIXSON, C. 'A Very Carefully Orchestrated Life': Dramatic Representations of and by Zelda Fitzgerald. American Drama, volume 11, no 1, p. 32-57, 2002.

WIXSON, C. Ragged Edges: The Curious Case of F. Scott Fitzgerald's The Vegetable. American Drama, volume 15, no 2, p. 48-60, 2006.

WOLF, M. Introduction: The emergence of a sociology of translation. In: FUKARI, A. (Eds.) Constructing a Sociology of Translation. New York/Amsterdam: John Benjamins, 2007, p. 1-36. 